\title{
Colonialismo, deportación de cubanos y raza en tiempos de paz (1864-1867)*
}

\author{
por \\ Juan Luis Bachero Bachero ${ }^{1}$ \\ Universitat Jaume I
}

El presente trabajo examina como a partir de 1864, siendo Capitán general de Cuba Domingo Dulce, comenzó una política de deportaciones de delincuentes e individuos considerados de «mal vivir». Se analiza asimismo a través de las fuentes documentales del Ministerio de Ultramar, los papeles de la colonia de Fernando Poo y los generados en la propia Cuba, cómo las autoridades antillanas justificaron las deportaciones apelando a un supuesto incremento en la criminalidad, que les permitió imponer un orden social cada vez más restrictivo en momentos de incertidumbre socioeconómica y política. La importancia de la deportación como método de control social se incrementaría en 1866 con el comienzo de una grave crisis económica, una situación social todavía más degradada, una expansión del independentismo y un nuevo Capitán general, Francisco Lersundi, de tendencia más conservadora. Estas actuaciones no pueden estar desligadas de las teorías criminológicas de la época, que determinaron la salida de la colonia de los deportados, el modo en que se llevó a cabo y las condiciones a las que fueron sometidos en los puntos de remisión.

Palabras Clave: deportación de Cuba; delincuentes reincidentes; Fernando Poo; década de 1860; control social; Capitán general de Cuba.

Cómo Citar este artículo / Citation: Bachero Bachero, Juan Luis, "Colonialismo, deportación de cubanos y raza en tiempos de paz (1864-1867)", Revista de Indias, LXXIX/276 (Madrid, 2019): 521-549. https://doi.org/10.3989/revindias.2019.016.

* Trabajo realizado gracias a la beca FPU/MECD (AP12/02505). El autor está adscrito al grupo de investigación Historia Social Comparada de la Universitat Jaume I de Castellón de la Plana.

1 bacheroj@uji.es, ORCID iD: https://orcid.org/0000-0002-5376-7446. 
LaS DEPORTACiONeS. UNA POLÍTICA DEL CAPITÁN GENERAL

En primer lugar, cabría explicar que entendemos por deportación. Al hablar del término nos referimos a la acepción del siglo XIX, que continua en la actualidad, aunque la evolución social y política ha incorporado otras y ha hecho perder vigencia a esta. Entendemos por deportación el embarque forzado de uno o varios individuos con destino a un punto ultramarino perteneciente al mismo Estado, generalmente una colonia, en el que los sujetos permanecían con cierto grado de libertad y en el que la tutela de las autoridades continuaba y la prohibición de salir se mantenía. Relegación, confinamiento y destierro se han empleado como sinónimos.

En el contexto internacional, la década de 1860 comenzaba de una forma poco esperanzadora para el poder colonial español en Cuba. En abril de 1861 empezó la Guerra de Secesión en los Estados Unidos, en la que esclavitud fue uno de sus elementos más importantes. La decimotercera enmienda, propuesta en 31 de enero de 1865 y ratificada en 6 de diciembre de ese mismo año, ya finalizada la guerra, proclamaba la abolición en todo el país. La derrota de los confederados impulsó los movimientos abolicionistas en el continente. En España, el inicio de la contienda en los Estados Unidos supuso que las autoridades se plantearan la posibilidad de duración real de la esclavitud y el futuro de la isla sin ella, aunque tratando de alargar la conservación de esta institución ${ }^{2}$.

La intención de mantener la esclavitud a toda costa implicaba el incremento del temor a que se produjeran revueltas de esclavos. El 9 de septiembre de 1863, El Capitán general de Cuba, Domingo Dulce, pedía al teniente gobernador de Guanajay que investigara prudentemente el «descontento o excitación» entre las dotaciones de su jurisdicción. En febrero de 1864 se ordenaba a los capitanes generales de partido aumentar la vigilancia en los ingenios y fincas, dada la noticia de que habían entrado agentes de Santo Domingo para promover una insurrección y se trasladaba a los hacendados la necesidad de una mayor vigilancia. En julio de 1864 se descubrió un conato de insurrección en el partido de El Cobre, en oriente. En noviembre de ese mismo año, el gobernador político de Puerto Príncipe informaba de que se estaba preparando una insurrección de negros entre los que se presumía complicados a algunos blancos. En marzo de 1866, el Capitán general temía que los incendios en el partido de La Sabanilla hubiesen sido realizados por esclavos ${ }^{3}$.

\footnotetext{
2 Piqueras y Sebastià, 1991: 251-287.

3 Expediente relacionado con los temores de levantamientos de negros, Archivo Nacional de Cuba, La Habana (ANC), Donativos y Remisiones, caja 749, sig. 34. Expediente sobre el
} 
En referencia a la supuesta «excitación» en Guanajay, el teniente gobernador explicaba que no había el menor indicio. En la insurrección de El Cobre fueron aprehendidos cuatro esclavos, número que no indicaba una rebelión importante. En Puerto Príncipe, las sospechas terminaron con tres esclavos detenidos que «se sublevaron en demanda de libertad». Fueron condenados a 100, 50 y 25 azotes respectivamente y a llevar grillete y cadena en la finca de su dueño durante dos años el primero, uno el segundo y seis meses el tercero. El castigo se realizó en presencia de dos esclavos de las principales fincas de la jurisdicción. Parece indiscutible que se les utilizó con fines ejemplarizantes y que denominarlo insurrección o conspiración resulta excesivo. El proceder recogía el pánico existente ante una rebelión de esclavos, pero la conspiración de mayor envergadura de la década fue posterior, la del poblado de El Cobre, en junio de 1867, protagonizada por esclavos y pardos libres, 26 de ellos fueron condenados a distintas penas 4 .

El temor a que las circunstancias internacionales se trasladaran al interior, llevó al Capitán general a pedir el 28 de febrero de 1864 la potestad para trasladar a la Península o islas adyacentes a los naturales que fueran criminales reincidentes, presidiarios cumplidos y licenciados del ejército de «mala nota» ${ }^{5}$. El 30 de marzo demandaba que no se permitiera regresar a los presidiarios cubanos cumplidos de los presidios africanos con penas superiores a cuatro años, o que al menos se consultara su regreso a las autoridades coloniales. El 14 de febrero de 1865, con la Guerra de Secesión casi finalizada y con una situación muy complicada para las tropas españolas en Santo Domingo, Dulce reiteraba las peticiones incidiendo en que la fatal influencia que ambas contiendas habían tenido entre la gente de color hacia previsibles perturbaciones en la isla. El efecto fue el esperado y mediante real orden de 20 de agosto de 1865 le fueron concedidas las facultades pedidas, con la condición de que los futuros represaliados pudieran elegir pasar a la Península o trasladarse a cualquier otro punto del extranjero $^{6}$. Tales medidas tenían un alcance limitado por los pocos individuos a los que implicaban, pero mostraban las intenciones de la máxima autoridad colonial.

proyecto de conspiración en Puerto Príncipe entre la raza de color, ANC, Comisión Militar Ejecutiva Permanente, leg. 124, exp. 4.

4 Franco, 1974: 40.

5 Oficio de Gobernador superior civil de Cuba a ministro de Ultramar, 28 de febrero de 1864, Archivo Histórico Nacional, Madrid (AHN), Ultramar, leg. 4718, exp. 5.

6 Informe de la sección de Ultramar del Consejo de Estado, 26 de mayo de 1864, AHN, Ultramar, leg. 4718, exp. 5. 
El miedo a una rebelión esclava, injustificado, facilitó que Dulce consiguiera los poderes especiales que pretendía, pero según sus propias peticiones la medida iba encaminada hacia la represión de un perfil diferente de hombres: delincuentes reincidentes e individuos tenidos como de «mala nota». De igual modo manipulaba la información referente a los puntos de destino. En la carta de 28 de febrero de 1864 indicaba que isla de Pinos estaba llena con los 200 deportados que había allí y que el erario público no podía hacerse cargo de su subsistencia y trabajo. Pero en realidad, el número de relegados en aquel momento era de $70^{7}$, cifra muy inferior a los 600 sujetos de «mal vivir» que había en 1844, cuya alimentación era satisfecha por la administración ${ }^{8}$.

Dulce era un hombre de trayectoria liberal templada, por lo que cabría preguntarse el motivo de su insistencia en conseguir unas facultades tan extraordinarias. Su motivación tendría que ver con la situación en la isla y su percepción de que se estaba degradando. Los libres de color se oponían la discriminación que sufrían y la ansiada libertad no llegaba a los esclavos. En el campo cubano crecía el desorden, la política colonial generaba descontento y el independentismo incrementaba su apoyo por la existencia de intereses divergentes entre la mayoría de los cubanos y el Gobierno colonial, el estancamiento económico y unas cargas fiscales que los criollos consideraban abusivas. Dulce, buen conocedor de la maquinaria política española, procedió a dar las explicaciones para anticiparse y convencer a las autoridades peninsulares, cuando resultaba evidente que las deportaciones no eran el modo más adecuado de luchar contra las conspiraciones de siervos. A los esclavos no se les imponían penas fuera de Cuba.

Para legitimar su actuación recurrió a un artículo de José Antonio Saco en La América, publicado el 12 de enero de 1864, en el que el autor, basándose en los datos de criminalidad en 1862, daba la alarma del elevado número de asesinatos y de delitos impunes y establecía la idea de que la legislación no era suficiente para ponerles coto. Asociaba la delincuencia a chinos y libres de color, de acuerdo con una estadística publicada en La Habana, y proponía la disminución de la raza africana con una serie de medidas que solo afectaran a las personas de color: que los delincuentes no pudiesen volver tras cumplir su condena en la Península o los presidios africanos, que los vagos fuesen enviados a la Península o a Fernando Poo para que se les utilizara en beneficio del Estado. Además, pretendía que todos los esclavos liberados menores de 30 años salieran de la isla, fomentar la emigración de los libres

7 Estado de deportados a 29 de febrero de 1864, ANC, Gobierno Superior Civil, leg. 1451, n. ${ }^{\circ} 56910$.

8 Expediente sobre confinados a Pinos, AHN, Ultramar, leg. 4627, exp. 9. 
de color y que no se permitiese regresar a cualquiera de raza africana que hubiera salido de la isla por cualquier motivo. En un nuevo artículo, publicado un mes después, se mostró contrario a la presencia de chinos en la isla9.

El artículo de Saco, publicado un mes antes de la primera petición del Capitán general, coincidía en situar el problema de la delincuencia en Cuba y el modo de atajarla. Fue editado en una revista dirigida a un público elitista y pensado para influir en el Gobierno, por lo que tuvo una gran resonancia y causó una enconada controversia entre personalidades importantes de la isla, un sector social del cual el Gobierno esperaba apoyo incondicional. Saco manipulaba la realidad al asociar la delincuencia con la cuestión racial y al desvincularla de las condiciones de vida y nivel cultural. Trató de magnificar los delitos, utilizándolos para promover una política de blanqueamiento que nada tenía que ver con la criminalidad, ya que no contemplaba la deportación de la isla de los delincuentes blancos y sí la de personas de color sin delitos.

Los estudios relativos al nivel de criminalidad se centran en otros periodos o no analizan en profundidad la década de $1860^{10}$. Según las estadísticas oficiales, en 1861 se registraron 4.576 delitos y 4.322 al año siguiente. A pesar del leve descenso, en este último año aumentaron los homicidios hasta un total de 174. Los robos y hurtos eran los más frecuentes, alcanzando un total de 2.471 en 1861 por 2.267 en 1862 , año en que el $57 \%$ de los delitos habían sido en poblado y el $43 \%$ en despoblado, mostrando que la extensión de la delincuencia era un fenómeno difundido tanto en el ámbito rural como en el urbano, aunque ligeramente más importante en las ciudades ${ }^{11}$. En realidad, los niveles de delincuencia en 1861 y 1862 eran prácticamente similares, por lo que la criminalidad en sí misma no explicaba la adopción de estas medidas especiales ${ }^{12}$.

Saco fue hábil al poner el tema en el centro del debate para influir en la política gubernamental, pero el Capitán general se aprovechó de ello para cohesionar a la sociedad en torno a la necesidad de reprimir a los tenidos por indeseables. Se quería conseguir el asentimiento de las clases medias, urbanas, blancas, generalmente escandalizadas con estas actuaciones delictivas. Esto suponía la criminalización de la población de color y los asiáticos, cuyo papel en Cuba era subsidiario al ocupar los puestos más bajos del escalafón social.

9 Saco, 1864a; $1864 \mathrm{~b}$.

10 Respecto a los estudios de la delincuencia en Cuba cabe resaltar Díaz Martínez, 2003: 3-18; 2005. Sobre el bandolerismo ver Paz Sánchez, Fernández Fernández y López Novegil, 1993-1994. También Balboa Navarro, 2003.

11 Armíldez de Toledo, 1864, "Estadística criminal".

12 Acerca de la violencia institucional en la sociedad burguesa ver Gómez Bravo, 2005: 13-24. Bennassar, 1997. Arostegui, 1994: 17-55. 
Las autoridades coloniales siempre habían pretendido contar con el apoyo de los criollos, obviando al resto de grupos raciales con los que lo que se pretendía atemorizar a los blancos. Para conseguirlo se procedió a la creación del perfil del delincuente, precisamente para darles visibilidad ${ }^{13}$. Con esto se pretendía desviar la atención sobre otras cuestiones políticas y económicas para focalizarla sobre la delincuencia, presentándola en niveles insoportables. De este modo, nominalmente se aumentaba la inseguridad de la sociedad y se mostraba un Gobierno que actuaba supuestamente para defender los intereses de las gentes honradas. Así, el incremento en la vigilancia y las consiguientes injerencias del poder resultaban más tolerables ${ }^{14}$. Estas actuaciones tenían un indudable trasfondo político por la asociación que se hacía en la época entre delincuencia y disidencia política, según la cual se pensaba que, en caso de motines, revueltas e insurrecciones estas capas de excluidos participaban en las mismas.

Una vez obtenida la potestad que pretendía, el 28 de marzo de 1866 embarcó a 42 individuos deportados a Cádiz en la fragata Hernán Cortes. Eran 16 blancos, seis mulatos y 20 negros, con una edad que oscilaba entre los 21 y los 52 años. Se trataba de cuatro canarios, un peninsular y el resto cubanos, todos de La Habana excepto tres. Los actos que habían cometido eran variados, pero casi todos estaban relacionados con la reincidencia en delitos de «poca monta» y faltas menores. La mayoría por hurtos, robos y vagancia, pero también encontramos agresiones, tenencia de armas prohibidas, embriaguez, estafa, falsificación de moneda, reyertas, heridas, resistencia a la autoridad y un caso de secuestro. Entre los delitos más graves encontramos a un hombre que había cometido asesinato, otro acusado de homicidio y un tercero al que se atribuía un intento del mismo delito ${ }^{15}$.

Lo expuesto por Saco se recogió en cuanto a la adopción de medidas excepcionales y a la fijación de la Península y Fernando Poo como lugar de remisión de relegados. Pero la puesta en práctica difirió en cuanto al perfil de los afectados al no hacer distinción entre las distintas razas. La composición racial de los deportados evidencia que la neutralización del «peligro negro» no era su objetivo principal. De hecho, este supuesto riesgo era cada vez

13 Foucault, 2002: 174. Para Foucault y su vigencia en la historia social, véase Vázquez García, 1997: 145-159.

14 Trinidad Fernández, 1993: 71-73.

15 Oficio del Gobernador superior civil de Cuba a ministro de Ultramar, 28 de marzo de 1866. "Estado de los individuos que en virtud de la autorización concedida por real orden de 20 de agosto del año pasado son extrañados de esta isla", en Informe de la sección de Ultramar del Consejo de Estado, 26 de junio de 1866, AHN, Ultramar, leg. 4718, exp. 5. 
menor, ya que el porcentaje de población de color en la isla había pasado del $58,5 \%$ en 1841 a un $43,7 \%$ en 1862 . Aunque se mantuvo estable en términos absolutos, 589.333 en 1841 y 594.488 en 1862, su peso relativo disminuía a causa de la inmigración blanca. Por otro lado, dentro de la población de color aumentaba el peso de los libres, 152.838 en 1841 y 221.417 en 1862 , lo que representaba en este último año una proporción del $37,2 \%{ }^{16}$. La tendencia de la población dificultaba cada vez más la hipotética posibilidad de reproducir la insurrección haitiana en la Antilla mayor.

Una salida considerable de gente de color, incluso tratándose de libres, no era conveniente por cuanto hubiera podido ser percibida como un intento de blanqueamiento del país. Algo no deseado por los grandes hacendados entre los que crecía la demanda de mano de obra ${ }^{17}$. Los cerca de nueve meses pasados desde la obtención del permiso hasta la puesta en práctica de las deportaciones muestran que las concibió como una herramienta a la que recurrir en el caso de considerarlo necesario. Cuando esto ocurrió, procedió a realizar un envío de pocos individuos con una intención intimidatoria, pero que a su vez serviría de ensayo por si la situación política y social se degradaba. Además, la situación del Capitán general era cada vez más precaria por la oposición del sector más integrista que demandaba mano dura contra los criollos. Por esto, el embarque puede también interpretarse como una concesión del Capitán general a dicho grupo en aras de reforzar la propia posición.

Cuando las autoridades en la Península tuvieron conocimiento de su salida, se dispuso que fueran desembarcados en Ceuta y Melilla donde serían distribuidos proporcionándoseles recursos para su sostenimiento. El Gobierno se mostraba favorable a que pasaran a las repúblicas americanas o en su defecto a otras posesiones españolas ${ }^{18}$, pero para el Capitán general de Cuba la mejor opción era enviarlos a territorio español ya que hacerlo a otros países próximos le podía suponer un conflicto y lo más probable era que no los admitieran.

Autorizar a la máxima autoridad de un territorio ultramarino a deportar a quienes supuestamente comprometieran la continuidad de su estatus era una

16 Resumen del censo de población de la isla de Cuba a fin del año de 1841, 1842: 19. Armíldez de Toledo, 1862: 2 y 8.

17 Torres-Cuevas et al., 1996: 4. Los intentos de los esclavistas para introducir mano de obra en el periodo posterior a la Guerra de los Diez Años, en Balboa Navarro, 2000.

18 Nota a oficio del Gobernador superior civil de Cuba a ministro de Ultramar, 28 de marzo de 1866. Nota a oficio de ministro de la Gobernación a gobernador de Cádiz, 7 de mayo de 1866, AHN, Ultramar, leg. 4718, exp. 5. 
cosa, pero que esto sirviera para que fuera la colonia la que se deshiciera de sujetos tenidos por criminales a costa de cargárselos a la metrópoli, era bien distinto y contra natura, en cuanto a las relaciones coloniales se refiere. Portugal, Reino Unido y Francia habían utilizado repetidamente a sus posesiones ultramarinas para deshacerse de delincuentes y opositores políticos. La Península había servido de lugar de confinamiento político de cubanos, pero estos una vez en su destino no representaban un peligro, cosa que no sucedía con aquellos que se pensaba que podían delinquir.

Los acontecimientos iban en la línea contraria a lo pretendido por el poder colonial español. En Santo Domingo, después de menos de dos años de conflicto, la debilidad de la metrópoli se manifestaba con rotundidad: el 15 de julio de 1865 las tropas españolas abandonaban la isla tras una ingente cantidad de dinero gastado y una cifra de bajas cercana los 15.000 hombres $^{19}$.

En Cuba, el 26 de marzo se celebraron las votaciones para la Junta de Información con la elección de 12 reformistas sobre 16. La derrota fue compensaba con los comisionados de libre designación. Pero, aun así, implicaba que habría representantes que pretendían llevar a cabo una política de reformas en una metrópoli que no las quería y sin la necesaria estabilidad política para abordarlas. En oriente, arrendatarios, hacendados y ganaderos vivían un proceso de empobrecimiento y entre ellos había empezado a extenderse la idea de la abolición ${ }^{20}$. La reacción del Gobierno español fue designar como Capitán general a Francisco Lersundi, conocido por su ultraconsevadurismo, con el cual comenzaría una etapa caracterizada por la represión ${ }^{21}$.

El 18 de julio ordenaba la aprehensión de 200 negros libres y 200 asiáticos, escogidos de entre los de conducta «más depravada» para llevarlos respectivamente a Fernando Poo y a «su país». Justificaba esta medida en la gran cantidad de «negros libres y esclavos y algunos blancos» que se dedicaban a la delincuencia. Sin embargo, la composición racial de los delincuentes no se cumpliría ya que entre los que saldrían en la fragata Rosa del Turia en 14 de agosto había 66 blancos, 21 mulatos y 69 negros ${ }^{22}$. La remisión de asiáticos se suspendió. Además, los delincuentes en La Habana no eran tan numerosos

19 Moreno Fraginals, 1993: 83.

20 Ibarra Cuesta, 2009: 38-56.

21 Casanovas Codina, 2000: 108.

22 Relación de los individuos deportados de este territorio y embarcados hoy en la barca mercante Rosa del Turia con destino a la isla de Fernando Poo, AHN, Ultramar, leg. 4718, exp. 5. Oficio del Tribunal de cuentas al contador de hacienda de la isla de Cuba, 14 de diciembre de 1882, Archivo General de la Administración, Alcalá de Henares (AGA), África-Guinea, caja 81/7077. Fueron escoltados por 130 hombres. 
ya que para llenar el barco tuvieron que recurrir a traer a unos 100 de los que había deportados en isla de Pinos $^{23}$.

Observamos que, pese a que se engloba a muchos blancos, hay entre los deportados, tal y como sucedía en el primer envío, una sobrerrepresentación de los hombres de color, que proporcionalmente rondaban el $43 \%$ de la población y fueron el $57,7 \%$ de los represaliados. Esto tiene que ver con una mayor proporción de la gente de color entre la delincuencia, por la diferente posición social y nivel cultural de los mismos ${ }^{24}$.

El nuevo Capitán general no desaprovechó la herramienta conseguida por su predecesor, especialmente cuando la situación política se estaba tensando. El 17 de abril de 1866, antes de la actuación de un tenor catalán, en el teatro se profirieron gritos de «Fuera gorriones», en referencia a los peninsulares, tras lo cual se produjo una pequeña refriega ${ }^{25}$. El 19 de abril hubo incidentes en el Teatro de Tacón, cuando durante la lectura del poema titulado Adiós a $C u b a$, de Alfredo Torroella, se oyeron voces dando vivas a Cuba que fueron respondidas con exclamaciones de «Viva España», produciéndose un alboroto que duró hasta que intervino la policía. Los gritos y respuestas continuaron en la calle y posteriormente en el café El Louvre, terminando con la detención de dos individuos por haber gritado «Muera España» y con la orden de arresto para otros $12^{26}$. Actos de desafío como estos no se habían producido con anterioridad, lo que las autoridades interpretaron como un aumento de la inseguridad política.

La coyuntura económica también se complicaba. A principios de 1866 el precio del azúcar había bajado hasta los niveles de 1853 por el fuerte crecimiento en la producción de dulce de remolacha. La crisis financiera que se produjo ese mismo año restringió profundamente la circulación de capitales, lo que tuvo unas evidentes consecuencias sociales ${ }^{27}$. El crecimiento de la masa

${ }^{23}$ Expediente sobre el embarque de negros y chinos, ANC, Gobierno Superior Civil, leg. 1451, Núm. 56905. Expediente sobre chinos que no trabajan, ANC, Gobierno Superior Civil, leg. 1451, n. $^{\circ} 56902$.

24 Saco, 1864a. Las diferencias entre ambos grupos se incrementaron a finales de siglo con la afluencia a la ciudad de muchos esclavos liberados, ver Díaz Martínez, 2005: 60-61. La desproporción entre razas en la delincuencia contribuiría a que ya a principios del siglo XX, autores como Fernando Ortiz o Israel Castellanos consideraran que la raza era un elemento fundamental en la explicación de la delincuencia, ver Naranjo Orovio y Puig-Samper, 1998.

25 La Esperanza, Madrid, 14 de mayo de 1866.

26 Expediente relativo a los desórdenes ocurridos en el Teatro de Tacón en La Habana en la noche del 20 de abril de 1866, AHN, Ultramar, leg. 4648, exp. 34. Los detenidos deberían pagar una multa o pasar un mes en la cárcel.

27 Le Riverend, 1974: 423-424. Marrero, 1985, vol. XII: 305-308. 
de excluidos incrementó el temor de las elites a un aumento de la conflictividad social, lo que reactivó la represión de la vagancia.

Según Justo Zaragoza, Lersundi ordenó

... prender a todos los vagos y viciosos apuntados en los registros de la policía, con la que de continuo luchaban, y particularmente de los que se distinguían con la clasificación de incorregibles, por haber sufrido más de cinco prisiones. Acordado el plan de leva y cuando los agentes de la autoridad pudieron detener en la cárcel a todos los criminales de la capital se dispuso su embarque en la fragata Rosa del Turia ${ }^{28}$.

Algunos pidieron que la medida se extendiera a los independentistas, pero según afirmaba, tal medida

... no fue necesaria (...) porque después de cerrarse los comités y de verse que la deportación de la mala gente era un hecho, todos usaron en lo sucesivo la mayor prudencia temiendo que la medida gubernativa se extendiera a otras clases sociales ${ }^{29}$.

Castigar a un grupo para atemorizar a otros muchos fue una constante en la práctica de las relegaciones. En este caso se eligió a aquellos que habían cometido delitos o faltas de orden público en el pasado, a pesar de que algunos estaban plenamente reinsertados. Esto supuso una grave conculcación de derechos de unos hombres que situados en el escalafón social más bajo no tenían a nadie que les defendiera. El castigo ejemplarizante podía entenderse como una declaración genérica de que se actuaría a toda costa para mantener el orden público, extendiendo el efecto disuasorio a la disidencia política. El resultado no puede tildarse de satisfactorio para los intereses de la metrópoli, más allá de un breve periodo, puesto que dos años más tarde comenzaría una nueva guerra para obtener la independencia.

Los delincuentes apresados continuaban siendo juzgados según las leyes ordinarias y después de cumplir la pena impuesta podían reincorporarse a la sociedad $^{30}$. Las deportaciones se plantearon desde un punto de vista gubernativo para sacar de Cuba a un grupo social determinado. Contra algunos de ellos podían emplearse las leyes contra la vagancia. Pero en muchos casos ante la falta de preceptos legales no se les podría haber incriminado, por lo que se obvió la legalidad y se actuó administrativamente. Además, se impuso el mismo castigo para todos, sin distinguir entre aquellos que habían cometi-

28 Zaragoza, 1873, tomo II: 156.

29 Ibidem: 157. Los comités a los que se refiere son los reformistas.

30 Trujillo Monagas, 1882, vol. I: 25-36. 
do delitos graves como homicidio de otros que simplemente eran pobres o alcohólicos.

La respuesta al primer envío desaconsejaba la Península como destino. Durante el mandato de Dulce continuaron enviándose algunos individuos a isla de Pinos, pero precisamente lo que se pretendía evitar era que fueran destinándolos a esta isla tan cercana, desde donde al cumplir el periodo estipulado los relegados volvían a casa. El objetivo era aislarles totalmente de la sociedad cubana $^{31}$. En este sentido, Fernando Poo tenía un mayor carácter intimidatorio y proporcionaba al destierro un carácter prácticamente definitivo.

La fragata elegida era propiedad de la empresa Zulueta \& Cia, que desde 1859 había obtenido la concesión del aprovisionamiento de la colonia de Fernando Poo y que convirtió a la misma en la base de su comercio negrero. El capitán elegido fue Francisco Viñes, sobrino del capitán negrero de Julián Zulueta, Eugenio Viñes. El enorme acopio de víveres, así como los antecedentes del capitán y de la empresa, hizo recaer sobre la expedición indicios fundados de que a su regreso había introducido esclavos en la isla. Tanto que el ministro de Ultramar pidió explicaciones a la máxima autoridad colonial, a lo que el sucesor de Lersundi, Joaquín del Manzano, respondió con evasivas $^{32}$. Los traficantes aprovechaban cualquier oportunidad para introducir bozales y la salida de un barco con dirección al golfo de Guinea representaba una buena oportunidad de negocio en el viaje de regreso. El beneficio era doble por cuanto se deshacían de un grupo social que el sistema era en buena parte incapaz de asumir, e incorporaba a otro destinado a ser explotado.

La política de Lersundi fue seguida por Joaquín del Manzano, aunque con matices. Tras la experiencia de la Rosa del Turia, los traslados fueron menos cuantiosos. En 30 de junio de 1867 embarcó en el vapor correo Canarias con destino a Vigo a otros 16, entre blancos y de color. El 5 de agosto, igual número fueron despachados en el vapor Hernán Cortes con dirección al mismo $\operatorname{lugar}^{33}$. Fueron los últimos envíos, ya que en 12 de mayo de 1867, una real orden ordenaba al Capitán general que se abstuviera de remitir «criminales reincidentes» a Fernando Poo $^{34}$. Teóricamente no se prohibía deportar, pero cuando los dos barcos llegaron a la Península se exigió a la máxima autoridad colonial que restringiera esta práctica por la inconveniencia de la permanencia de sujetos de mal vivir en la metrópoli. Con la opinión del Gobierno en con-

31 Díaz Martínez, 2012: 147.

32 Piqueras Arenas, 1992: 473-478 y 468.

33 Oficios de Gobernador superior civil de Cuba a ministro de Ultramar, 30 de junio y 15 de agosto de 1867, AHN, Ultramar, leg. 4718, exp. 5.

34 Rodríguez San Pedro et al., 1868, tomo X: 34. 
tra, durante el mandato de Blas Diego de Villate y en el segundo periodo de Lersundi no se produjeron relegaciones de estas características, configurándose como una práctica discontinua y no plenamente planificada.

\section{LAS ISLAS FILIPINAS, DESTINO FINAL DE LOS DEPORTADOS CUBANOS A LA PENÍNSULA}

La creación de un perfil de delincuente como respuesta a una determinada situación política, económica y social, no fue un constructo determinado únicamente por la voluntad de los capitanes generales. La criminalización y represión sobre determinados grupos: borrachos, vagos, mendigos o prostitutas fue habitual en la Europa del siglo XIX. Se trataba de magnificar los delitos asociados a las clases bajas como los pequeños robos o la embriaguez para facilitar el control social de los pobres ${ }^{35}$. Detrás había toda una concepción del delincuente como un ser degenerado cuyo comportamiento tenía una base biológica y por tanto su rehabilitación era imposible ${ }^{36}$. Esta percepción de la extrema peligrosidad del delincuente y de la imposibilidad de su reinserción social se aprecia en las vicisitudes de los relegados y determinó en una manera muy importante lo que sucedería con ellos en sus lugares de destino.

El grupo de cubanos que se encontraba en Ceuta y Melilla fue embarcado hacia las Filipinas. Las plazas africanas eran territorios con frecuentes conflictos fronterizos y con gran importancia del elemento militar. Allí cumplían condena los reos peninsulares con los delitos más graves, que eran obligados a realizar trabajos de fortificación de la plaza. Los relegados, en cambio, dado que no recaía sobre ellos ninguna sentencia condenatoria, no podían permanecer presos ni ser empleados en realizar trabajos forzados, de ahí la presión castrense para forzar su salida. Así, fueron llevados a Cádiz y embarcados en la fragata Concepción que zarpó el 27 de marzo de 1867. Según las órdenes transmitidas al Gobernador superior civil de Filipinas, debían ser distribuidos por las distintas islas y provincias donde permanecerían libres, estableciéndolos de modo que se garantizara la tranquilidad de la colonia ${ }^{37}$. Los que habían sido trasladados en los barcos Hernán Cortes y Canarias a mediados de 1867

35 Lawrence, 2004: 212.

36 Estas ideas fueron recogidas por Lombroso considerado el padre de la criminología que en 1876 escribió El hombre delincuente. Sus influencias provienen de la frenología, la teoría de la degeneración de Bénédict Morel y el evolucionismo de Charles Darwin y Herbert Spencer.

37 Real orden de 18 de diciembre de 1866. Real orden de 4 de marzo de 1867, Relación nominal de los cuarenta deportados que procedentes de la isla de Cuba, se han embarcado hoy en la fragata mercante Concepción, Orden del Ministerio de la Guerra de 22 de marzo de 1867 y Despacho del ministro de la Guerra a Gobernador superior civil de Cuba, 24 de 
fueron embarcados en la urca Santa María con destino a Manila en la segunda quincena de noviembre de 1867. Las órdenes eran que a su llegada fueran distribuidos en los puntos en que su estancia resultara menos peligrosa ${ }^{38}$. La política seguida con sus predecesores quedó establecida como oficial.

El 11 de julio de 1867 llegó a Manila la Concepción, que además de los deportados llevaba a militares y empleados civiles para la administración de la colonia $^{39}$. En la prensa, al describir la llegada de la fragata no se mencionaba su caso. Justo lo contrario de lo que sucedía en el caso de las deportaciones por motivaciones políticas. Los opositores eran defendidos por sus afines y atacados por los contrarios, lo que permitía que sus casos fueran conocidos y facilitaba su retorno una vez disminuían las tensiones políticas. Estos deportados cubanos, llegaron a un país al que no había otros relegados de su nacionalidad y tampoco recibirían la solidaridad de los peninsulares, ya que, en lo referente a las colonias, las disensiones entre partidos pasaban a un segundo plano y lo verdaderamente importante era la salvaguarda de los intereses de la metrópoli, lo que implicaba no cuestionar las decisiones expeditivas de los capitanes generales.

A su llegada a Filipinas, fueron trasladados a la cárcel de Bilibit, en el extremo norte de la isla de Luzón, donde permanecieron presos contraviniendo las órdenes recibidas. El Capitán general justificaba esta medida en no perjudicar la buena opinión de los españoles, ya que según expresaba los nativos los calificaban de «peninsulares negros». La Marina se negó a emplearles aduciendo que carecían de fondos. Diecisiete de los cubanos elevaron una instancia a la Intendencia general de Hacienda para trabajar en la fábrica de tabacos, explicando que eran maestros tabaqueros, petición les fue denegaba por no considerar prudente que trabajaran en las fábricas del Estado. Finalmente se decidió distribuirlos entre las distintas provincias, ubicando a cada uno de ellos en una diferente. Allí, las autoridades debían vigilarlos estrechamente para que no expandieran ideas contra el orden público y social, así como proporcionarles trabajo y medios de subsistencia ${ }^{40}$.

abril de 1867, AHN, Ultramar, leg. 4718, exp. 5. Dos no fueron embarcados por enfermos, José de los Reyes Pérez, uno de ellos, murió poco después.

38 Oficio del gobernador de Cádiz a ministro de Ultramar, 26 de noviembre de 1867 y Real orden de 2 de diciembre de 1867, AHN, Ultramar, leg. 4718, exp. 5. Ambos se refieren a 31 relegados, excluyendo a un presidiario de Ceuta que también debía ser embarcado, esto puede ser porque finalmente no lo hizo o porque fue embarcado al margen de la lista confeccionada para ello.

39 El Imparcial, Madrid, 17 de septiembre de 1867. El Lloyd Español, Madrid, 18 de septiembre de 1867.

40 Minuta de Ministerio de Ultramar a Gobernador superior civil de Filipinas, 8 de noviembre de 1867, AHN, Ultramar, leg. 4718, exp. 5. 
Con el veto a su utilización como mano de obra en la manufactura más poderosa del archipiélago, controlada por el Estado ${ }^{41}$, las posibilidades de procurarse su manutención disminuían ostensiblemente, empujando a muchos de ellos a la marginalidad. En la colonia existía abundancia en la disponibilidad de mano de obra y los relegados no podían ser utilizados en trabajos forzados, lo que determinaba que debían trabajar por un sueldo. El temor exagerado que se les profesó hizo que las autoridades fueran trasladándose de unas a otras el problema que su presencia significaba. En Filipinas, las máximas instancias gubernativas mantenían la misma perspectiva respecto al orden público que en Cuba, remitiéndoles a las autoridades provinciales que lidiaron con un único deportado. Los afectados, cuyos derechos se vulneraban a cada paso que daban, fueron privados incluso de la compañía de sus compañeros de infortunio y castigados con el aislamiento.

Aun así, el lugar de destino no puede considerarse definitivo. Antonio Labrador fue destinado a Pampanga, Cirilo Pachecho a Burias, José Castillo a Abra, y Federico Martínez en Unión. En 1874 todos se encontraban en Balabac $^{42}$, en el propio archipiélago filipino, lo que no variaba las condiciones en que se encontraban ni su propia condición de deportados. Teniendo en cuenta las escasas excepciones en que pudieron eludir su destino, en la práctica se configuró en la mayoría de los casos como un castigo perpetuo en el que los sujetos podían permanecer en libertad. Esto les obligaba a conseguir su manutención en un entorno con escasas oportunidades laborales, lo que podía resultar peor que una condena a presidio en la que los reos tenían su subsistencia asegurada.

El destino de unos y otros varió en función de las circunstancias. Juan Bautista Mena, apresado a la edad de 48 años, tras habitar en distintas provincias y hallarse en la más absoluta miseria, ingresó en el Hospicio de San José. Antonio Labrador, Cirilo Pacheco y José Castillo también subsistieron de la caridad pública ${ }^{43}$. Esto demuestra el incumplimiento de las autoridades locales del deber de socorrerles y proporcionarles medios de trabajo y subsistencia.

41 Fradera, 1999: 200-202.

42 AHN, Ultramar, leg. 4771, exp. 12: «Antonio Labrador, Cirilo Pacheco y José Castillo, deportados cubanos y fallecidos en Balabac (Filipinas)». AHN, Ultramar, leg. 4771, exp. 14: «Federico Martínez, deportado cubano a las islas Filipinas (falleció)».

43 AHN, Ultramar, leg. 5221, exp. 37: «Juan Bautista Mena (deportado)». Mena fue deportado por «vagancia, embriaguez, reyerta y armas prohibidas». AHN, Ultramar, leg. 4771, exp. 12: «Antonio Labrador, Cirilo Pacheco y José Castillo, deportados cubanos y fallecidos en Balabac (Filipinas)». 
Resulta innegable que muchos de ellos vivían en malas condiciones y que eran un estorbo para las autoridades que no se aprovecharon de su fuerza de trabajo. Sin embargo, pronto se abrió una posibilidad de utilización de los deportados. Los problemas que causaba la piratería con base en la isla de Joló al comercio español y la creciente presión de otras potencias sobre el archipiélago joloano llevaron al Capitán general de Filipinas, José Malcampo, a organizar una campaña en 1876 con el objeto de acabar con el filibusterismo y reforzar el dominio español sobre el mismo ${ }^{44}$. Esto ofreció a los deportados peninsulares cantonales y a los cubanos la posibilidad de enrolarse en el ejército a cambio del levantamiento del confinamiento al terminar la campaña ${ }^{45}$.

\section{Los deportados cubanos en Fernando Poo}

En el momento de la llegada de los deportados cubanos, Santa Isabel estaba escasamente habitada por europeos. La población era de 578 hombres y 280 mujeres en 1858, que se incrementó a 938 y 285 respectivamente en 1869 , de los que ese último año únicamente había 90 varones y 2 mujeres blancas. La población estimada del resto de la isla era de unos 15.000 habitantes, todos negros excepto algunos misioneros ${ }^{46}$. El precario estado en la colonización de Fernando Poo dificultaba acoger con las mínimas garantías a los confinados.

El 3 de octubre se produjo la llegada de la Rosa del Turia a su destino. El gobernador de Fernando Poo, José Gómez Barreda, no tardó en reaccionar explicando que la colonia estaba escasa de víveres y de dinero. A su llegada fueron colocados temporalmente en el pontón y poco después trasladados al cayo Enríquez, frente a Santa Isabel, por el miedo que habían despertado entre colonos y aborígenes. Allí se habían de construir dos barracones con separación de blancos y negros y un hospital provisional y cada grupo estaría controlado por capataces. El gobernador de la isla manifestó que su intención era ponerlos a trabajar en obras públicas, especialmente a los negros, pero que no disponía de herramientas ni de materiales ${ }^{47}$. Según la descripción de un relegado político cubano en Fernando Poo, el cayo tenía: «iDOCE varas de largo por $\mathrm{OCHO}$ de ancho! (...). Aquel cayo se movía y estaba

44 Álvarez Gutiérrez, 1997: 268-290.

45 Expediente sobre indulto de deportados, AHN, Ultramar, leg. 5222, exp. 2.

46 De Castro Antolín y De la Calle, 2007: 16-18. Informe de la Comisión nombrada por el gobernador de Fernando Poo en 5 de mayo de 1860 para la exploración de la isla, 1861: 44.

47 Oficios de gobernador de Fernando Poo a ministro de Ultramar, 3 y 31 de octubre de 1866, AHN, Ultramar, leg. 4718, exp. 5. 
totalmente rodeado de tiburones cuyas espoletas múltiples contemplábamos horrorizados» ${ }^{48}$.

Poco después de la llegada de la Rosa del Turia, desembarcaron otros 19 procedentes de la Península, en la urca Marigalante $^{49}$. Se trataba de un grupo de demócratas y republicanos que habían sufrido la represión tras la revuelta de San Gil, en junio de 1866. El gobernador de la colonia tuvo una actitud bien diferente hacia ellos, pues a su arribo les dejó libres y les conminó a procurase alojamiento, hospedando a los que no lo consiguieron en una cabaña que servía de almacén a la estación naval. A todos se les concedió una ayuda de ocho reales diarios para hacer frente a sus necesidades. Los peninsulares pudieron deambular por la isla y aunque fueron vigilados por el intendente de la policía y los oficiales de la guarnición, se relacionaban entre sí, con la población de la colonia y con las autoridades españolas ${ }^{50}$.

La ayuda otorgada a los peninsulares contrastaba con el trato que se dio a los cubanos. En Fernando Poo, la peligrosidad de los confinados políticos era nula y al tratarse de un territorio colonial con una escasa población europea su integración resultaba fácil. Su carácter de disidentes perdía importancia al formar parte de un grupo que se encontraba en minoría numérica aplastante. Los aspectos raciales y culturales primaban sobre las posibles diferencias políticas en un entorno percibido como inquietante y actuaban como elemento cohesionador. Los cubanos formaban un grupo muy diferente al ser catalogados como criminales. Su elevado número en una colonia poco poblada hizo temer que delinquieran en la isla. Además, había que considerar su condición social, racial y su procedencia de una colonia, donde cualquier disidencia constituía una transgresión que las autoridades consideraban de mayor calado.

Aun así, algunos cubanos pudieron obtener pequeños privilegios, permitiéndoles «pasar a tierra» por su buena conducta ${ }^{51}$, lo que les permitió ganarse paulatinamente la confianza de las autoridades y relacionarse con otros integrantes de la colonia, facilitándose que su situación en la isla principal se consolidara. Algunos se casaron con nativas o se establecieron en la colonia

\footnotetext{
48 Sifredo y Llópiz, 1893: 25.

49 Una urca es un tipo de embarcación grande y muy ancha en el centro, que generalmente se usa para el transporte de mercancías.

50 Oficio del gobernador de Fernando Poo al ministro de Ultramar, 30 de octubre de 1866, AGA, África-Guinea, caja 81/6941. Biografías de los diputados a Cortes de la Asamblea constituyente de 1869, con los retratos de los mismos perfectamente litografiados por los principales artistas de esta capital, 1869, tomo I: 733-735.

51 Diario de Sesiones de las Cortes, 9 de julio de 1869, https://app.congreso.es/est_sesiones/.
} 
y un joven de La Habana por «su honradez, su inteligencia y su laboriosidad ha logrado inspirar la mayor confianza y estimación en la oficina de Hacienda, de la que es empleado». Ganarse la confianza tendría que ver con el comportamiento. Lo expuesto anteriormente sobre los deportados políticos podría haberse extendido a los cubanos, aunque con una dificultad mayor. En un entorno donde los blancos eran tan solo unos pocos, los que observaran buena conducta tendrían mayores posibilidades de mejora, lo que no excluía a mulatos y negros que por tener ciertas cualidades pudieran ser útiles, como tener capacidad de liderazgo o inspirar temor o respeto entre sus compañeros. Ser empleado en la isla principal constituía una recompensa ya que el resto se encontraban en el islote «tan haraposos en su mayor parte, tan depauperados física y moralmente, que daba lástima verlos $»^{52}$. Según otro testimonio:

\begin{abstract}
... vemos un pequeño cayo que oímos entonces decir se halla denunciado como inseguro a causa de estar socavada toda su base; en la cima del cayo hay una barraca de grandes dimensiones; a la puerta de ella vemos a algunos hombres blancos completamente desnudos, que agitaban al aire un lienzo blanco; creímos que nos saludaban, mas luego supimos que aquellos desgraciados eran deportados criminales mandados por Lersundi, que se valían de todo aquel medio siempre que pasaba alguna canoa o bote, para pedir que les llevaran agua que beber ${ }^{53}$.
\end{abstract}

Estas condiciones determinaban un aprovechamiento muy escaso de su fuerza de trabajo en beneficio del Estado, a pesar de tener un perfil similar al de los deportados británicos a Australia ${ }^{54}$. Sin embargo, en Fernando Poo, la escasez en la dotación, la ausencia de medios y herramientas y la falta de planificación determinaron que su presencia no supusiera un empuje a la colonización. Los beneficios que se pensó que podrían aportar fueron menores que el temor que se les profesaba, especialmente debido a la oposición que su estancia causó entre los comerciantes y los jefes indígenas. De hecho, incluso se concedió al Capitán general la facultad de trasladarlos a Annobon o a cualquier otra isla bajo su mando ${ }^{55}$.

La prolongación de la estancia suponía era muy grave porque su permanencia suponía un grave riesgo para la salud agravada por las condiciones en que vivían. A mediados de 1859 había llegado una expedición para proceder a la colonización de la isla. Azotados por las fiebres 17 murieron y 92 regre-

52 Balmaseda, 1869: 153-154.

53 Bravo Sentíes, 1869: 76-77.

54 Brooke y Brandon, 2005: 89-93.

55 Oficio del gobernador de Fernando Poo a ministro de Ultramar, 1 de abril de 1867, AHN, Ultramar, leg. 4718, exp. 5. Rodríguez San Pedro et al., Legislación ultramarina, tomo X: 34 y 52 . 
saron en diciembre de ese mismo año, estableciéndose solo ocho. En 1861, de los 151 miembros de la guarnición 22 habían muerto y 83 eran inútiles para el servicio. Los continuos fracasos en la colonización llevaron a realizar una expedición desde Cuba de 200 emancipados negros. Cinco años más tarde tan solo subsistían $116^{56}$. La teoría de la mayor aclimatación de los negros al clima tropical en la práctica no funcionaba ${ }^{57}$.

En 1867 se produjo una nueva epidemia de fiebre amarilla que obligó a abandonar el pontón Perla, principal foco de la infección y que era utilizado como prisión. En 1868, la pandemia continuaba, falleciendo en el primer trimestre un deportado, un paisano y 18 marinos y en abril dos misioneros, dos marineros, dos desterrados y once soldados de la compañía ${ }^{58}$. La plaga que diezmaba la guarnición y la ausencia de lugar habilitado para prisión añadió argumentos para el fin de su situación. La incomodidad de tener a un elevado número de sujetos catalogados como criminales en la colonia, su peculiar situación jurídica y el gran esfuerzo que se estaba haciendo para procurar su subsistencia, eran elementos que hacían la situación insostenible. La solución fue la de embarcarlos hacia cualquier punto que no fuera España, sus islas adyacentes o las posesiones ultramarinas ${ }^{59}$. La alternativa planteada era cuanto menos rocambolesca, porque significaba tratar de endosar a otros países a un grupo muy numeroso de españoles tratados como auténticos criminales. Tras más de año y medio, las autoridades gubernativas reflexionaban acerca de qué se debería hacer con ellos. Su situación constituía un hecho inusual que aconsejaba una solución definitiva.

En mayo de 1868 quedaban en la isla un total de 153 deportados, de los que únicamente ocho o diez estaban integrados en la vida de la colonia. Junto a ellos podrían permanecer otros siempre que hubieran observado buena conducta, arrepentimiento y laboriosidad ${ }^{60}$. El premio al buen comportamiento consistió en posibilitarles la elección de permanecer en una colonia en estado ruinoso o pasar al extranjero. El resto fueron embarcados con rapidez,

56 De Castro Antolín, 1994: 10.

57 Existían en la época teorías seudocientíficas que insistían en los aspectos raciales como elementos que posibilitaban e imposibilitaban la aclimatación a trabajos en los climas tropicales, ver Naranjo Orovio y García González, 1996: 69-83.

58 Cuadro estadístico del movimiento y necrología de enfermos ocurrida durante el primer trimestre de 1868 en el Hospital militar del Príncipe. Defunciones ocurridas desde el último parte, 29 de abril de 1868, AGA, África-Guinea, caja 81/6962. Iglesias Pardo, 1874: 14.

59 Real orden de 2 de julio de 1868, AHN, Ultramar, leg. 4718, exp. 5.

60 Oficio del gobernador de Fernando Poo a ministro de Ultramar, 20 de mayo de 1868 y nota a la misma del negociado de Gobernación de Cuba, AHN, Ultramar, leg. 4718, exp. 5. 
iniciándose el proceso 26 de julio. El reembarque constituía una nueva vulneración de sus derechos, pero al menos suponía poner fin a su deplorable situación y les permitía decidir a dónde querían dirigirse. La elección dio como resultado dos embarques con pocos hombres dirigidos a territorios portugueses y otros más numerosos a ciudades bajo la autoridad británica. La propia celeridad por deshacerse de ellos dificultó su propósito, puesto que transportando a un número reducido la probabilidad de que fueran aceptados era mayor. El éxito del intento dependía además de la opinión de las autoridades de los otros países y de la prevención que estas pudieran tener para contradecir a las autoridades españolas. Por otro lado, las expulsiones hacían probable que estos confinados intentaran volver a su lugar de origen en cuanto pudieran (tabla 1).

\section{TABla 1. SAlidas de los Deportados haCia El EXTRANJERO}

\begin{tabular}{|l|r|c|c|}
\hline Nombre del barco & N. $^{\circ}$ de deportados & Destino & Coste individual del billete \\
\hline Africain (francés) & 6 & Isla del Príncipe & - \\
\hline Calabar (inglés) & 31 & Liverpool & 12 libras \\
\hline Calabar (inglés) & 7 & Madeira & 8 libras y 6 chelines \\
\hline San Antonio & 34 & Sierra Leona & (buque de la armada española) \\
\hline
\end{tabular}

Fuente: elaboración propia, datos tomados de Oficios del gobernador de Fernando Poo a ministro de Ultramar, 29 y 30 de agosto y 26 de octubre de 1868, Oficio del ministro de Estado a Ministerio de Ultramar, 19 de diciembre de 1868, AHN, Ultramar, leg. 4718, exp. 5.

Antes del traslado se les proporcionó vestimenta adecuada, ya que muchos de ellos se encontraban desnudos o vestían ropas harapientas. Con los transportados a Sierra Leona llegó una carta del gobernador de Fernando Poo, Joaquín Souza Gallardo, para el gobernador británico pidiéndoles que los aceptara, argumentando que tenían oficios útiles y que fueron deportados gubernativamente sin tener causa alguna. La entrada les fue denegada ya que el mandatario inglés consideró inaceptable que recogiera relegados de otros países cuando se había estipulado que los suyos no fueran enviados a las colonias y que la manera en que habían sido tratados solo podía imponerse a grandes criminales ${ }^{61}$. Es llamativa la contestación del gobernador inglés, por

61 Diario de Sesiones de las Cortes, 9 de julio de 1869, https://app.congreso.es/est_sesiones/. Relación de los deportados que procedentes de la isla de Cuba son trasladados desde 
cuanto se refiere reiteradamente a estos como represaliados políticos; la causa, la carta que hábilmente trató de camuflar las verdaderas razones de su traslado a la colonia, pero que no engañó a la máxima autoridad inglesa. Este intento se extendería al resto de los envíos, prueba de la manera de hacer del Gobierno en esta cuestión que considerando a este grupo de cubanos como criminales utilizaron todas las estratagemas posibles para tratar de trasladarlos a otros países.

La prohibición de entrada en Sierra Leona tuvo dos consecuencias. La primera, para los cubanos pasajeros del barco, que el Capitán del barco trasladó a Cádiz, donde llegaron a finales de noviembre. La segunda fue para el plan proyectado de expeler a los cubanos. Temiendo que en Liverpool sucediera lo mismo, se suspendieron los embarques momentáneamente con destino a esta ciudad. En cambio, ocho que habían solicitado pasar a la isla del Príncipe estaban a punto de salir en un vapor de guerra francés que se prestó a llevarles por un módico precio ${ }^{62}$. La continuidad de los envíos a los territorios portugueses y la próxima salida de este grupo muestra que las tretas del gobernador engañaron momentáneamente a las autoridades portuguesas.

De los que aún permanecían en la isla, diez deseaban pasar a Madeira, 20 a Liverpool, nueve a México, nueve a Montevideo, diez a Monrovia y otro estaba enfermo. Esto hace un total de 59 deportados, frente a los 86 que habían sido embarcados. A los que unido a los ocho que decidieron quedarse, deja 13 restantes de los que se desconoce su paradero y que presumiblemente correspondería a los fallecidos, dadas las enormes dificultades de fuga. De los que estaban pendientes de salida algunos lo consiguieron, un envío de seis salió con destino a Liverpool lo que indica que probablemente los de la primera remisión desembarcarían en la ciudad inglesa. En esta ocasión no tuvieron tanta suerte y el cónsul español pidió permiso para desviarlos a Tenerife, a lo que el Gobierno contestó que no podían llegar a ningún territorio español ${ }^{63}$.

La admisión de estas personas en los puntos elegidos era dificultosa. Pero también hemos de tener en cuenta el desinterés del gobernador de la colonia, puesto que los únicos lugares a donde habían salido barcos eran Sierra Leona, la

el cayo Enríquez a los puntos elegidos por los mismos que a continuación se expresan. Oficio del gobernador de Fernando Poo a ministro de Ultramar, 28 de agosto de 1868 y Oficio del ministro de Estado a ministro de Ultramar, 19 de diciembre de 1868, AHN, Ultramar, leg. 4718, exp. 5.

62 Telegrama del gobernador de Cádiz a ministro de Ultramar, 21 de noviembre de 1868 y Oficio del gobernador de Fernando Poo a ministro de Ultramar, 26 de octubre de 1868, AHN, Ultramar, leg. 4718, exp. 5. La Correspondencia de España, 27 de noviembre de 1868.

63 Oficio del ministro de Estado a ministro de Ultramar, 17 de marzo de 1869, AHN, Ultramar, leg. 4718, exp. 5. 
isla de Príncipe, Madeira y Liverpool. El resto habían quedado bloqueados cuando era evidente que desde Santa Isabel no era posible enviarlos a los lugares que habían especificado. Ni siquiera el triunfo en la Península de la Revolución de 1868 significó un cambio en sus condiciones. En cambio, el 22 de mayo de 1869 llegaron a la isla otros 250 relegados políticos cubanos en el San Francisco de Borja, lo que redoblaba la presión sobre la colonia. Súbitamente, sacar a los presuntos malhechores de Fernando Poo se convirtió en una necesidad apremiante por lo que se dispuso su salida inminente. El gobernador mantuvo en la isla el San Francisco de Borja, para que se dispusiera su embarque. Treinta y dos zarparon el 27 de mayo con destino a la Isla de Madeira y tras ser rechazados por las autoridades portuguesas se ordenó que recabaran en $\mathrm{Cádiz}^{64}$.

Su destino final fueron las Canarias, a donde arribaron 33 en agosto en medio de un gran revuelo de la prensa y quejas por parte de las autoridades. Fueron distribuidos del siguiente modo: 12 a Gran Canaria, de donde se remitieron cuatro a Fuerteventura y Lanzarote, y el resto en Tenerife desde donde se les distribuyó por las cuatro islas occidentales del archipiélago. Desde Las Palmas de Gran Canaria algunos fueron distribuidos hacia poblaciones del interior, siendo vigilados e imponiéndoles una ayuda municipal hasta que encontraron trabajo ${ }^{65}$. También con ellos se siguió una política en la que se les aislaba individualmente o en pequeños grupos, con la que se pretendía neutralizar su peligrosidad y que sirvió para facilitar su integración ya que entre ellos hubo únicamente un caso de robo en una iglesia. Dada la imposibilidad de enviarlos al extranjero, lugares como Ceuta y Canarias ofrecían la posibilidad de desembarque en lugares que formaban parte del país y que a la vez estaban alejados de la Península.

\section{EL FIN DEL PERIPLO: INDULTOS, RETORNOS A CUBA Y FALLECIMIENTOS}

$\mathrm{Al}$ acotar el espacio temporal en el título del artículo entre 1864 y 1867 nos referimos al periodo en el que tuvieron lugar las deportaciones desde Cuba a causa del temor al socavamiento del orden público. Sin embargo, hemos considerado interesante hacer un seguimiento de los deportados ya que la actuación posterior del Estado muestra con claridad el carácter represivo del mismo y nos permite ver globalmente lo que estas relegaciones significaron. Esto implica conocer las condiciones en que vivieron en los puntos de destino y en qué medida la medida les fue alzada o por el contrario alcanzó un carácter perpetuo.

64 Oficio del gobernador de Fernando Poo a Ministerio de Ultramar, 4 de junio de 1869, AHN, Ultramar, leg. 4718, exp. 5. Balmaseda, 1869: 153-155.

65 González Rodríguez, 1993: 713-714. 
Los deportados cubanos negros en Filipinas, Lorenzo Martínez y Martínez y José de la Paz Pallares, participaron en la campaña de Joló. Una vez finalizada la misma con el reconocimiento de la soberanía española por el sultán de Joló, a todos los cantonalistas que combatieron y presentaron buena conducta se les permitió el regreso a sus casas. Esto no se extendió a los cubanos, a los que se alzó el confinamiento a medias: podían salir del archipiélago filipino pero no volver a Cuba ${ }^{66}$. Andrés Díaz Rodríguez, embarcado en el Hernán Cortes a la edad de 22 años por «su laboriosidad y constancia en el trabajo ha sabido crearse una posición independiente y decorosa» en Ilocos Sur, donde residía vigilado por la autoridad. Díaz consiguió que se le indultase parcialmente en mayo de 1873, permitiéndole el regreso a la Península. Aun así, decidió permanecer voluntariamente en su lugar de residencia ${ }^{67}$. Las diferencias en el resarcimiento del destierro nos remiten al origen y la raza. A los peninsulares que progresaban económicamente mediante su trabajo se les facilitaba la conmutación del castigo impuesto. Pero también los individuos de color podían conseguirlo, era más difícil y pasaba por arriesgar su vida participando en una campaña militar combatiendo por un Estado que no había hecho sino conculcar reiteradamente sus derechos.

En la posibilidad de regreso también tuvo importancia el azar. Un caso anecdótico fue el de Valeriano Caballero, relegado con tan solo 20 años en los que acumulaba tres prisiones gubernativas y cuatro criminales, por hurto, vagancia, heridas, embriaguez, faltas a la policía y quimerista. En Nueva Écija su comportamiento fue similar. Se le acusó de participar en reyertas, asociarse con gente sospechosa, ser ratero y vago. Las autoridades filipinas lo deportaron de nuevo hacia la Península el 4 de noviembre de 1877, desde donde fue retornado a Cuba. La combinación de mal comportamiento, que podría estar motivado por falta de alternativas, con el temor y prejuicios determinaron que Caballero pudiera regresar a la Antilla mayor. En el lado opuesto se sitúa José Montiel, también relegado en Filipinas, que en diciembre de 1887 fue autorizado a volver a Cuba amparándose en su buena conducta y en el real decreto de indulto de 2 de enero de 1886 de relegados en la Guerra Chiquita ${ }^{68}$.

66 Expediente sobre indulto de deportados, AHN, Ultramar, leg. 5222, exp. 2.

67 AHN, Ultramar, leg. 5221, exp. 40: «Andrés Díaz Rodríguez (deportado)». Díaz fue deportado por realizar varios robos y hurtos, algunos en cuadrilla, así como por faltas a la policía, escándalo y «arribar a deshoras».

68 AHN, Ultramar, leg. 4780, exp. 26: «Valeriano Caballero, deportado cubano en Filipinas, embarcado para la Península por disposición gubernativa», Resumen de deportados a Filipinas y Marianas en 1874 y 1875. AHN, Ultramar, leg. 5222, exp. 3, Expediente sobre el regreso de deportados a Filipinas y Marianas: «Caballero zarpó de Filipinas en el Irurac Bat, el mismo 
En Fernando Poo, los deportados salieron de la isla o quedaron voluntariamente en la misma. En Filipinas, por el contrario, la salida de archipiélago fue puntual, por lo que la mayoría imposibilitados de regresar a sus casas perecerían a miles de millas de sus familiares. Federico Martínez, murió en la indigencia el 10 de octubre de 1874. Isidro Mendoza sucumbió el 10 de enero de 1877 en Tuguegarao, en la provincia de Cagayan. El mismo año fallecieron Placido Figueras, el 24 de enero en Balabac; Juan Bautista Mena, el 4 de febrero en el Hospital de San José de Manila, a causa de la enfermedad que padecía; el 9 de mayo Epifanio Blanco en la provincia de Nueva Vizcaya; y el 11 de octubre José Eleno Bretó en el Hospital de San Juan de Dios de Manila. A mediados de 1875 había fallecido en Ilocos Sur, Juan Patero Rodríguez. En el mismo lugar, a causa de una enfermedad feneció José Sicler, el 4 de marzo de 1879. Los que quedaban, irían muriendo paulatinamente, Crescencio Taibo falleció de disentería en Camarines Norte en mayo de 1882 y Pablo Pascasio Hermenteros lo hizo en 10 de febrero de 1884 en Tagbilaran, distrito del Bohol, a causa de una «congestión cerebral», casi 18 años después de su llegada ${ }^{69}$. En total, de los relegados a Filipinas, sabemos que dos pudieron regresar a Cuba, tres obtendrían permiso para trasladarse a la Península y diez fallecieron allí. El resto sufrirían el mismo final, ubicados en unas islas poco colonizadas en donde apenas pasarían barcos y estando vigilados por las autoridades, su fuga resultaba muy complicada.

Los relegados cubanos en Fernando Poo tuvieron mayores probabilidades de regresar a sus casas y a la Península. Los que habían conseguido pasar al extranjero probablemente regresarían a $\mathrm{Cuba}^{70}$. En Ceuta se encontraba un grupo que había sido llevado desde Cádiz, a los que se les permitió emigrar al extranjero si para ello no necesitaban pasar por la Península. Algunos permanecerían en el enclave español: José Aizcorve y José de la Luz Larin, consiguieron el regreso a Cuba en 3 de octubre de 1878 junto a los deportados

que en 1874 había transportados a 463 cantonalistas con destino a su deportación en Filipinas». AHN, Ultramar, leg. 4793, exp. 14: «José Montiel, deportado cubano en Filipinas».

69 AHN, Ultramar, leg. 4771, exp. 14: «Federico Martínez, deportado cubano a las islas Filipinas (falleció)». AHN, Ultramar, leg. 4743, exp. 9: «Isidro Mendoza, deportado cubano a Filipinas». AHN, Ultramar, leg. 4743, exp. 20: «Placido Figueras, deportado cubano a Filipinas». AHN, Ultramar, leg. 4743, exp. 6: «D. Juan Bautista Mena Brenes, deportado cubano a Filipinas». AHN, Ultramar, leg. 4743, exp. 14: «Epifanio Blanco, deportado cubano a Filipinas». AHN, Ultramar, leg. 4746, exp. 56: «José Eleno Bretó, deportado cubano a Filipinas». AHN, Ultramar, leg. 5225, exp. 27: «Fallecimiento del deportado cubano Patero Rodríguez». AHN, Ultramar, leg. 4795, exp. 27. «José Sicler, deportado cubano a Filipinas». AHN, Ultramar, leg. 4750, exp. 42: «Crescencio Taibo, deportado de la isla de Cuba en Filipinas». AHN, Ultramar, leg. 5254, exp. 23: «Se remite la partida de defunción del deportado cubano Pablo Pascasio Hermenteros».

70 Expediente del deportado Felipe E. González, AHN, Ultramar, leg. 4771, exp. 47. 
políticos de la plaza ${ }^{71}$. La gran presencia de deportados políticos cubanos en la Península y los enclaves africanos como consecuencia de la Guerra de los Diez Años facilitó el regreso de los que quedaban al producirse el fin de la contienda. Los que fueron acogidos en sus puntos de destino pudieron emigrar e incluso en algunos casos regresar a Cuba. Lo mismo sucedió con aquellos que no pudieron desembarcar y que tras recabar en territorio español se les dejó vía libre para emigrar al extranjero, configurándose la emigración como su alternativa principal. Esto supuso que el tiempo de confinamiento fuera mucho más bajo que en el caso de las remisiones a Filipinas.

Cipriano Bencomo, embarcado en la Rosa del Turia, y otros dos que le acompañaban fueron acusados de robo en un almacén de efectos de escritorio en Cuba, en junio de $1870^{72}$. En el mismo caso podríamos situar a Telesforo Ruiz, quien antes de su embarque había sufrido 23 correcciones en isla de Pinos. Tras su regreso fue de nuevo destinado allí, encausado a principios de 1873 por participar en dos homicidios ${ }^{73}$. De Bencomo y Ruiz sabemos que retornaron por producirse su detención, pero otros lo conseguirían y pudieron pasar desapercibidos. Aun así, el índice de retorno sería bajo a causa de la política gubernamental que tendía al olvido de los de Filipinas y pretendía la emigración de los relegados a Fernando Poo.

\section{CONCLUSIONES}

Durante la década de 1860 la situación política en Cuba era complicada. En el contexto internacional con el comienzo de la Guerra de Secesión en Estados Unidos en 1861 y la rebelión dominicana contra la anexión española en 1863. Esto determinó al Capitán general Domingo Dulce a pedir la facultad de realizar deportaciones de delincuentes habituales. La retirada de las tropas españolas de Santo Domingo, mostraba el decaimiento español y la derrota del sur en la guerra norteamericana, aumentaba la dificultad de mantener la esclavitud en la colonia.

Esta conjunción de factores alentó a los independentistas que en abril de 1866 cuestionaron abiertamente la dominación metropolitana. A principios de ese mis-

71 D. José Aizcorve y D. José Hernández, deportados, AHN, Ultramar, leg. 4769, exp. 3. José de la Luz Larin y José Aizcorve, deportados cubanos, solicitan indulto, AHN, Ultramar, leg. 4771, exp. 7.

72 Consejo de guerra contra Cipriano Bencomo, José Cabral y José Belén Acosta, AHN, Ultramar, leg. 4371, exp. 27.

73 Expediente sobre el traslado a isla de Pinos de varios individuos, AHN, Ultramar, leg. 4436, exp. 228. 
mo año, la bajada de los precios del azúcar y el desarrollo de una grave crisis financiera contribuyeron a aumentar el descontento. La respuesta de las autoridades fue la realización de una serie de relegaciones preventivas de hombres con antecedentes penales que habían cumplido sus penas. Se plantearon como deportaciones de gente de color y chinos, tratando de asociar a estos grupos raciales con la delincuencia en un intento de cohesionar a los blancos en torno a la fidelidad a España. Sin embargo, derivó en una deportación de antiguos delincuentes al margen de la raza, que tuvo influencia en los lugares de destino, en los que dentro de las enormes dificultades los blancos tuvieron en general un trato mejor.

El incremento de la oposición política a la dominación española derivó en la creación, por parte de las autoridades, de un perfil de delincuente y el destierro del grupo social de los excluidos, que no formaba la base del independentismo. Esto constituyó un aviso a la disidencia política de que se actuaría con severidad en caso de producirse intentonas armadas, pero a su vez muestra el despreció y el temor por estos individuos, de quienes se temía que pudieran ser utilizados por el independentismo.

La construcción de un perfil de delincuente susceptible de ser represaliado de manera arbitraria por las autoridades coloniales al margen de las leyes no puede ser separada de las corrientes criminales de la época que consideraban al reo como alguien cuya reinserción era poco menos que imposible. El concepto de la criminología de la época basado en el determinismo biológico del sujeto determinó las condiciones en los puntos de residencia, a pesar de que inicialmente fue concebida como un modo de establecer mecanismos de control social en Cuba. El miedo irracional frente a ellos derivó en un castigo que excedió del mero embarque y comprendió las condiciones en que residieron en los lugares de destino. Deportación y condiciones infrahumanas de vida no se corresponden con la naturaleza de los delitos cometidos, y adquirían mayor gravedad en el caso de los que ya habían cumplido condena.

\section{BIBLIOGRAFÍA}

Álvarez Gutiérrez, Luís, "Divergencias y acuerdos entre España, Gran Bretaña y Alemania sobre las islas de Joló", María Dolores Elizalde (ed.), Las relaciones Internacionales en el Pacífico (Siglos XVIII-XX), Madrid, CSIC, 1997: 268-290.

Armíldez de Toledo, conde de, Noticias estadísticas de la isla de Cuba, en 1862, La Habana, Imprenta del Gobierno, Capitanía general y Real hacienda, 1864.

Arostegui, Julio, "Violencia, sociedad y política: la definición de la violencia", Ayer, 13 (Madrid, 1994): 17-55. 
Balboa Navarro, Imilcy, Los brazos necesarios: inmigración, colonización y trabajo libre en Cuba, 1878-1898, Valencia, Centro Francisco Tomas y Valiente/Fundación Instituto de Historia Social, 2000.

Balboa Navarro, Imilcy, La protesta rural en Cuba. Resistencia cotidiana, bandolerismo y revolución (1878-1902), Madrid, CSIC, 2003.

Balmaseda, Francisco Javier, Los confinados a Fernando Poo e impresiones de un viaje a Guinea, Nueva York, Imprenta de la Revolución, 1869.

Bennassar, Bartolomé, "Conclusion", Jean Paul Duviols y Annie Molime-Bertrand (eds.), La violence en Espagne et en Amérique (XVe-XIXe siècles). Actes du Colloque international Les raisons des plus forts, París, Presses de l'Université de Paris-Sorbonne, 1997: s/p.

Biografias de los diputados a Cortes de la Asamblea constituyente de 1869, con los retratos de los mismos perfectamente litografiados por los principales artistas de esta capital, Madrid, Tomas Alonso, 1869, tomo I.

Bravo Sentíes, Miguel, Deportación a Fernando Poo. Relación que hace uno de los deportados, Nueva York, Hallet \& Breen, 1869.

Brooke, Alan y Brandon, David, Bound for Botany Bay: British convict voyages to Australia, Kew, The National Archives, 2005.

Casanovas Codina, Joan, ;O pan, o plomo! Los trabajadores urbanos y el colonialismo español en Cuba, 1850-1898, Madrid, Siglo XXI, 2000.

Castro Antolín, Mariano L. de, "Fernando Poo y los emancipados de La Habana", Estudios africanos, 8/14-15 (Madrid, 1994): 7-19.

Castro Antolín, Mariano L. de y Calle, $\mathrm{M}^{\mathrm{a}}$ Luisa de la, La colonización española en Guinea ecuatorial (1858-1900), Vic, Ceiba, 2007.

Díaz Martínez, Yolanda, "Criminalidad y violencia en la urbe habanera a finales del siglo XIX. Precisiones necesarias al respecto”, Rábida, 22 (Huelva, 2003): 3-18,

Díaz Martínez, Yolanda, La peligrosa Habana: violencia y criminalidad a finales del siglo XIX, La Habana, Editorial de Ciencias Sociales, 2005.

Díaz Martínez, Yolanda, "De marginados a trabajadores. Usos y destinos de la población penal en La Habana", Millars, 35 (Castellón de la Plana, 2012): 129-149.

Foucault, Michel, Vigilar y Castigar. Nacimiento de la prisión, Buenos Aires, Siglo XXI, 2002.

Fradera, Josep Maria, Filipinas, la colonia más peculiar. La hacienda pública en la definición de la política colonial, 1762-1868, Madrid, CSIC, 1999.

Franco, José Luciano, Ensayos históricos, La Habana, Editorial de Ciencias Sociales, 1974. 
Gómez Bravo, Gutmaro, Crimen y castigo: cárceles, justicia y violencia en la España del siglo XIX, Madrid, Catarata, 2005.

González Rodríguez, Candelaria, "Insurrectos Cubanos deportados hacia Canarias y Fernando Poo (1869): un ejemplo de deportación política", Actas III colóquio Internacional de História da Madeira, Funchal, Centro de Estudos de História do Atlântico, 1993: 703-719.

Ibarra Cuesta, Jorge, Patria, etnia y nación, La Habana, Editorial de Ciencias Sociales, 2009.

Iglesias Pardo, Luis, Observaciones teórico-prácticas sobre las fiebres africanas de Fernando Poo, precedida de una reseña histórico-geográfica de la isla, Ferrol, Taxonera, 1874.

Informe de la Comisión nombrada por el gobernador de Fernando Poo en 5 de mayo de 1860 para la exploración de la isla, Madrid, Imprenta Nacional, 1861.

Lawrence, Paul, "Policing the poor in England and France, 1850-1900", Clive Emsley y Eric Johnson (eds.), Social Control in Europe, vol. 2, (1800-2000), Columbus, The Ohio State University Press, 2004: 210-225.

Le Riverend, Julio, Historia económica de Cuba, La Habana, Pueblo y educación, 1974.

Lombroso, Cessare, L’homme criminel : étude anthropologique et psychiatrique, París, Félix Alcan, 1895.

Marrero, Leví, Cuba: economía y sociedad, Madrid, Playor, 1985, vol. XII.

Moreno Fraginals, Manuel, Guerra, migración y muerte (El ejército español en Cuba como vía migratoria), Colombres, Fundación Archivo de Indianos, 1993.

Naranjo Orovio, Consuelo y García González, Armando, Racismo e inmigración en Cuba en el siglo XIX, Aranjuez, Ediciones Doce Calles, 1996.

Naranjo Orovio, Consuelo y Puig-Samper, Miguel Ángel, "Delincuencia y racismo en Cuba: Israel Castellanos versus Fernando Ortiz", Carmen Ortiz y Rafael Huertas, Ciencia y Fascismo, Aranjuez, Ediciones Doce Calles, 1998.

Paz Sánchez, Manuel de, Fernández Fernández, José y Nelson López, Novegil, El Bandolerismo en Cuba (1800-1933). Presencia Canaria y protesta rural, La Laguna, Centro de la cultura popular canaria, 1993-1994, 2 vols.

Piqueras Arenas, José Antonio, La revolución democrática (1868-1874). Cuestión social, colonialismo y grupos de presión, Madrid, Ministerio de Trabajo y Seguridad Social, 1992.

Piqueras, José Antonio y Sebastià, Enric, Agiotistas, negreros y partisanos. Dialéctica social en vísperas de la Revolución Gloriosa, Valencia, Alfons el Magnànim, 1991.

Resumen del censo de población de la isla de Cuba a fin del año de 1841, La Habana, Imprenta del Gobierno, 1842. 
Rodríguez San Pedro, Joaquín, et al., Legislación ultramarina, Madrid, Manuel Minuesa, 1868 , tomo X.

Saco, José Antonio, "La estadística criminal de Cuba en 1862", La América, 8/1 (Madrid, 12 de enero de 1864).

Saco, José Antonio, "Los Chinos en Cuba", La América, 8/3 (Madrid, 12 de febrero de 1864).

Sifredo y Llópiz, Hipólito, Los mártires cubanos en 1869, La Habana, La Prensa, 1893.

Torres-Cuevas, Eduardo, et al., "La Revolución del 68. Fundamentos e inicio", María del Carmen Barcia, Gloria García y Eduardo Torres-Cuevas, Las luchas por la independencia nacional y las transformaciones estructurales. 1868-1898, La Habana, Editora política, 1996: 1-55.

Trinidad Fernández, Pedro, "La configuració històrica del subjecte delinqüent", Control Social. Teoria i Història. Papers del Centre per la Investigació dels Moviments Socials, Barcelona, Publicacions de la Universitat de Barcelona, 1993: 59-75.

Trujillo Monagas, José, Los criminales de Cuba y José Trujillo: narración de los servicios prestados en el cuerpo de policía de La Habana y historia de los criminales presos por él, en las distintas épocas de los distintos empleos que ha desempeñado hasta el 31 de diciembre de 1881, Barcelona, Fidel Giró, 1882, vol. I.

Vázquez García, Francisco, "Foucault y la Historia Social”, Historia Social, 29 (Valencia, 1997): 145-159.

Zaragoza, Justo, Las insurrecciones en Cuba, apuntes para la historia de esta isla en el presente siglo, Madrid, Manuel G. Hernández, 1873, tomo II.

Fecha de recepción: 22 de marzo de 2017.

Fecha de envío de las modificaciones: 22 de mayo de 2017.

Fecha de aceptación: 25 de mayo de 2017. 


\section{Colonialism, the deportation of Cubans, and race in peacetime (1864-1867)}

This article examines how, from 1864, in his role as Captain General of Cuba, Domingo Dulce initiated a policy of deporting criminals and "undesirables". It examines Overseas Ministry documentary sources, Fernando Poo's colonial papers and those generated in Cuba itself, to analyse how the colonial authorities justified the deportations appealing to a supposed increase in the crime rate, which allowed them to impose an increasingly restrictive social order in a period of socioeconomic and political uncertainty. The importance of deportation as a method of social control would increase in 1866 with the onset of a serious economic crisis, an even more depressed social situation, an expansion of the independence movement and a new, more conservative Captain General, Francisco Lersundi. These actions cannot be disassociated from criminological theories of the day, which determined deportees' departure from the colony, the manner in which this was done, and the conditions that they had to endure at points of referral.

KEY WORDs: deportation from Cuba; repeat offenders; Fernando Poo; 1860 's; social control; Captain General of Cuba. 